\title{
A Survey of Nurses' Knowledge of and Attitudes Toward Hospitalized Older Adults
}

\author{
Ya-Ling Shih ${ }^{1}$, Chia-Jung Hsieh ${ }^{1}$, Chia-Yu Li ${ }^{2}$, Chun-Wei Chang ${ }^{3} \&$ Yu-Ling Hsiao ${ }^{4}$ \\ ${ }^{1}$ School of Nursing, College of Nursing, National Taipei University of Nursing and Health Sciences, Taiwan \\ ${ }^{2}$ Taipei Veterans General Hospital, Taiwan \\ ${ }^{3}$ School of Medicine, Fu Jen Catholic University, New Taipei City, Taiwan \\ ${ }^{4}$ Institute of Nursing, Taipei Medical University, Center of Geriatric Care Resource, College of Medicine, Fu Jen \\ Catholic University, Taiwan \\ Correspondence: Chia-Jung Hsieh, PhD, RN, Associate Professor, School of Nursing, College of Nursing, \\ National Taipei University of Nursing and Health Sciences, No.365, Ming-te Road, Peitou District, Taipei City \\ 11219, Taiwan.
}

Received: May 11, 2021

Accepted: June 18, 2021

Online Published: June 29, 2021

doi:10.20849/ijsn.v6i2.896

URL: https://doi.org/10.20849/ijsn.v6i2.896

\begin{abstract}
Aim: To investigate the knowledge and attitudes of nurses towards older adults in the Taiwanese hospital.

Design: A descriptive correctional study.

Methods: A survey by random sampling of one teaching hospital for clinical nurses $(\mathrm{N}=80)$. The structural scales included demographic details, Palmore's Facts on Aging Quiz (PFAQ) knowledge scale, and Kogan's Old People (KOP) attitude scale. Lastly, we used Pearson's correlation analyses to identify the correlates.

Results: The rate of knowledge about aging was low at 55.76\%. However, the subjects held more favorable attitudes towards older adults (KOP score was 66.91). We also found that subjects who had better knowledge about aging also had a more positive attitude towards older adults.

The results can be used by nursing educators and managers to design courses on gerontology for nurses and nursing students, by providing data that can be utilized in decision-making regarding the effectiveness of nursing care provided to this growing group of older recipients.
\end{abstract}

Keywords: attitude, knowledge, older adults

\section{Introduction}

Industrialization has led to a demographic transition of fertility and mortality rates from high to low. Moreover, due to improvement in scientific knowledge and progress in medical technology, the average life span of people is increasing. Hence, the aging population is rapidly growing especially in developed countries as compared to other populations worldwide. In fact, the World Health Organization (WHO, 2017) expects that by 2050, one in five people will be 60 years or older, totaling to 2 billion people. The increase in the number of older adults has a direct effect on health care systems because more health care professionals are required necessary to serve the growing numbers of older people with chronic illnesses. However, the barriers in providing quality services to older adults are negative attitudes and lack of knowledge, which affect health care outcomes and decrease the efficiency of the service.

\section{Background}

Taiwan had already become an "aged country" in 1993. The proportion of older people (i.e., those aged 65 years and older) in the population was $15.44 \%$, while the aging index increased from $46.88 \%$ in 1993 to $121.36 \%$ in 2020, second only to Japan among Asian nations (The Ministry of the Interior, 2020). The average lifespan in Taiwan went from 77.19 years old in 1992 to 84.05 in 2018 for women, and 71.78 years old to 77.55 for men (The Ministry of the Interior, 2020). The increasing longevity of the population means more and more people are entering the fourth age: a period when illness and medical problems can impinge on the individual's independence and quality of life. Hence, more and more healthcare professionals, especially nurses, are needed. 
However, according to a systematic review on majority of studies conducted in developed countries, it was found that professionals and undergraduate students in the field of healthcare have negative attitudes towards older adults (Che et al., 2018; Maximiano-Barreto et al., 2019). Rush et al.(2017) indicated that hospital nurses' attitudes towards caring for older adults and contributing factors to their attitudes was imperative to inform approaches for improving nurse' attitudes and supporting quality care for older adults.

Ageism influences the attitudes of nurses towards older adults. This is detrimental since pervasive ageist attitudes and stereotypes contribute to negative health outcomes on their physical and mental health (Burnes et al., 2019).Moreover, ageism among health care professionals can also result in discriminatory practices that place the elderly at risk as regards mortality, poor functional health, and slower recovery from illness (Burnes et al., 2019; Meisner, 2012). Hence, the World Health Organization (WHO, 2017) stated that combating ageism must lie at the core of any public health response to the aging population.

In Taiwan, $64.88 \%$ of older people have chronic diseases. Moreover, they constitute $37.2 \%$ of the inpatients while accounting for the highest proportion in total health insurance at $45.5 \%$ (The Ministry of Health and Welfare, 2018). Their population is increasing at a phenomenal rate; thus, nurses can expect to find older patients in both the hospital and community settings. Early surveys have suggested that increased knowledge in gerontology would help foster positive attitudes towards older adults (Campbell, 1971; Heller \& Walsh, 1976). Hope (1994) and Sheffler (1995), by using the Palmore's Facts on Aging Quiz (PFAQ) knowledge scale and the Kogan's Old People (KOP) attitude scale, found that higher knowledge scores on the subjects would mean higher attitude scores as well. Moreover, Mellor et al. (2007) indicated that there was a significant correlation between the attitudes of the participants and their knowledge about older people, as can be seen on their PFAQ scores $(r=0.596 ; p<0.001)$. Moreover, a review article reported that the attitudes and knowledge of emergency department nurses toward the aging processes might affect therapeutic interactions between the nurses and older adults (Deasey et al., 2014). As age increases, a human's physical condition declines; hence older adults are at high risk of getting sick. Caring for older adults has a significant impact on their well-being, quality of life, health, and mortality (Uğurlu et al., 2019).Thus, nurses must have adequate knowledge of their condition, not to stereotype them, and provide care modeled to fit their individual needs.

To date, there is little information on the knowledge and attitude of nurses toward older adults, thus threatening the future of the quality of care given to them. Therefore, the purpose of this study was to investigate the knowledge and attitudes of nurses towards older adults in the hospital setting, and to identify the relationship between knowledge score and attitudes score.

\section{Research Question}

We outlined the questions of this project below:

(1) What is the relationship between nurses' knowledge and attitudes towards older adults?

(2) What is the relationship between demographic factors and nurses' knowledge about aging?

(3) What is the relationship between demographic factors and nurses' attitudes towards older adults?

\section{Method}

We used a survey approach in this descriptive correlational study.

\subsection{Study Population}

We used a research method which focused on teaching hospitals in the private region. The sampling frame listed the target population that was about 450 nurses who work in 12 different settings. However, the sample settings excluded those in the baby room, operation room, pediatrics unit, and obstetrics and gynecology unit because nurses who work within these four settings do not directly care for older adults. We estimated the final sample size by calculating the standard deviation $(S D)$ in the pilot study. We used random sampling to give each unit in the target population a calculable probability of being selected. Thus, we distributed 92 questionnaires wherein 80 were returned, for a response rate of $86.96 \%$.

\subsection{Pilot Study}

As these questionnaires were developed in Western countries (i.e. United States and the United Kingdom), we had to translate, revise, and expertly validate them. Thereafter, we conducted a pilot study with a small sample size $(n=20$, return rate: $100 \%)$ in a teaching hospital located in a similar region in Taipei. We used this to test the scales for reliability, determine expert validity, and to ensure that the items within the scales correlate and complement each other in terms of coverage and response rates. Moreover, its purpose is to ensure that the respondents understand the questions and instructions, and to check whether the information collected can be 
analyzed.

\subsection{The Instrument}

The questionnaire was comprised of three parts: 1.) the demographic information, 2.) the scales of knowledge, and 3.) attitudes.

\subsubsection{Demographic Details}

We collated information about the respondents on the factors identified in the literature which potentially predict their knowledge and attitudes toward older patients. We presented demographic details of the sample which include age, religion, experience of living with the elderly, family structure, setting, working position, working experience, educational background, gerontological education, gerontological continuing professional development (CPD), and preferred patients' age group, among others.

\subsubsection{Palmore's Facts on Aging Quiz (PFAQ)}

We measured the variable of knowledge by using a modified version of Palmore's Facts on Aging Quiz (PFAQ; Palmore, 1977) which consists of 25 questions. The modifications were based on Courtenay and Wiedemann's (1985) suggestion that a "don't know" category be added, and following Hope (1994), respondents were asked to choose one of three options ("agree," "disagree," and "don't know") to enhance its validity. We made another modification based on the wording of the question on demographic data to account for current information, while some parts of questions 7, 9, 11, 25 were changed to adapt to Taiwanese circumstances. Responses to the PFAQ were recoded and assigned a score: +1 for a correct response, -1 for an incorrect response, and 0 if the respondent signified that they did not know (minimum -25 , maximum +25 ). The key to the correct answer is that all the odd-numbered items are false and all of the even-numbered are true. In scoring the knowledge portion, a higher score reflects better knowledge.

\subsubsection{Kogan's Old People Scale (KOP)}

Kogan's Old People Scale (KOP) is a Likert scale which contained 17 pairs of statements, where one of each pair is framed positively and the other negatively. Respondents were asked to indicate the extent of their agreement on a 4-point scale ( 1 for highly agree, 2 for agree, 3 for disagree, and 4 for highly disagree). All the odd-numbered items are negative ( +1 for highly agree, +2 for agree, +3 for disagree, and +4 for highly disagree) while all the even-numbered items are positive ( +4 for highly agree, +3 for agree, +2 for disagree, and +1 for highly disagree), where the minimum is 34 and the maximum is 136. In interpreting the results, higher scores indicated more positive attitude. Items $1,2,9,10,23$, and 24 are concerned with the residential aspects of old people's lives. Items $3,4,15$, and 16 reflect the participants' feelings and experience in the company of old people. Items $21,22,25$, and 26 that old people vary among one another. Items 17, 18, 19, 20, 31, and 32 implied interpersonal relations across age generations - conflicted or benign. Items $7,8,33$, and 34 represents the theme of dependence. Items 5, 6, 11, and 12 refer to the cognitive style and capacity of old people. Items 27, 28, 29 , and 30 cited qualities of old people with respect to personal appearance and personality. Finally, Items 13 and 14 do not readily cluster with any of the other items (Kogan, 1961).

\subsubsection{Validity}

We used expert validity for the type of internal validity. Moreover, we translated the questionnaires into Taiwanese and changed some of the questions in order to suit our current circumstances. After translation, two gerontological experts who knew English and Taiwanese reviewed the tools. The reviewers evaluated each item for clarity, concision, degree of difficulty, accuracy, relevancy, and reasonability. They rated the levels of easiness or difficulty from 1 to 4 , and the items over 3 points on the scale were used. The revisions followed the experts' suggestions.

\subsubsection{Reliability}

The pilot study was based on 20 nurses who worked in the medical ward of a regional teaching hospital in Taipei. The respondents were asked whether they felt any aspects of the questionnaires needed revising, as well as their analysis of the returned questionnaires. For the pilot study $(n=20)$, the reliability coefficient of the PFAQ knowledge score was $r=0.67$. Although acceptable levels of Cronbanch alphas are usually 0.7 to 0.9 , the PFAQ score range of $r=0.64$ to $r=0.68$ was very close. Hence, $r=0.67$ in this study was also acceptable. Furthermore, the level of Cronbach's alphas for the KOP attitude score was $r=0.81$, which was acceptable. In the formal study, the level of Cronbach's alpha was $r=0.79$.

\section{Analysis}

All of the data was coded and entered into the computer statistical package SPSS-PC for Windows 20.0. 
(1) Descriptive analysis has been used to describe the demographic details of nurses, PFAQ knowledge scales, and KOP attitudes scales such as frequency, percentage, mean, range, and $S D$. As a large number of statistical analyses were used in this study, the descriptive techniques of the mean, percentage, $S D$, and range, were utilized in order to describe the samples and scales, and to enhance the understanding of the samples' characteristics on both scores.

(2) Inferential analysis has been carried out using Pearson's correlation to determine the relationship between the PFAQ scales and the KOP scales, as Pearson's correlation is the most usual method by which the relation between the two variables is quantified. A comparison between the subjects' means of knowledge and attitude scores, and their demographic variables such as age, religion, experience of living with older people, family structure, setting, work position, work experience, educational background, gerontological education, gerontological CPD, and preferred patient's age group were carried out to examine these variables. A one-way analysis of variance (ANOVA) was used to examine the level of significance between these variables, and a Scheffe test was used to carry out multiple comparisons between dependent variables (i.e., knowledge and attitudes) and factors (i.e., demographic details).

\section{Ethics}

The research procedure and instructions were explained to the participating nurses before the survey. Their written consent was obtained after studying a cover letter that included the aims of the research, procedure, confidentiality (i.e., the researcher would keep all records closed and only persons involved in this research would have access to them), what the research involved in relation to the respondents, a statement saying that they were free to withdraw at any time, and that they could ask any questions about this study.

\section{Results}

\subsection{Participant Characteristics}

The participants consist of 80 nursing staff members from a 383-bed hospital for the elderly in central Taipei. Their characteristics are presented in Table 1 . They were all female, majority of them are over 25 years old (76.2\%), and have had living experience with the elderly (55.0\%). Moreover, on their professional characteristics, most of them have worked in a non-medical ward (66.2\%), were registered nurses $(91.2 \%)$, and have worked for over three years $(76.2 \%)$. Half of the participants have an educational background on gerontology, while only a minority preferred practicing it (7.5\%). Lastly, only 15\% participated in gerontological CPD.

\subsection{Knowledge of and Attitudes of Nurses Toward the Elderly}

\section{Association between demographic and professional characteristics and knowledge scores}

In Table 1, the results showed that younger participants demonstrated significantly more knowledge than older nurses in total knowledge score and psychological aspects score. The other results demonstrate no significant differences in total score after considering their relevant demographic and professional characteristics. However, on psychological knowledge, the participants with gerontological CPD demonstrated significantly more knowledge than those without.

Table 1. Participants' demographic characteristics and knowledge of the elderly $(n=80)$

\begin{tabular}{lllllllllll}
\hline Frequency & Percent & knowledge & \multicolumn{2}{l}{ Physical } & \multicolumn{2}{ll}{ psychological } & society & epidemiological \\
\hline$(n)$ & $\%$ & Mean $t / F$ & Mean $t / F$ & Mean & $t / F$ & Mean & $t / F$ & Mean & $t / F$ \\
& & $(S D)$ & & $(S D)$ & & $(S D)$ & & $(S D)$ & $(S D)$ & \\
\hline
\end{tabular}

\begin{tabular}{|c|c|c|c|c|c|c|c|c|c|c|c|c|}
\hline \multicolumn{13}{|c|}{ Socio-demographic characteristics } \\
\hline Age & & & & $2.44 * *$ & & -0.43 & & $2.17 *$ & & 1.60 & & 1.69 \\
\hline \multirow[t]{2}{*}{$<=25 \mathrm{y} / \mathrm{o}$} & 19 & 23.8 & 5.26 & & 2.11 & & 2.11 & & 1.47 & & -0.42 & \\
\hline & & & $(7.76)$ & & $(1.05)$ & & $(2.94)$ & & $(2.74)$ & & $(3.11)$ & \\
\hline \multirow[t]{2}{*}{$>25 \mathrm{y} / \mathrm{o}$} & 61 & 76.2 & 2.13 & & 2.25 & & 0.79 & & 0.51 & & -1.41 & \\
\hline & & & $(3.60)$ & & $(1.31)$ & & $(2.90)$ & & $(2.15)$ & & $(1.87)$ & \\
\hline Religious & & & & -0.66 & & -0.90 & & -1.17 & & 0.15 & & 0.60 \\
\hline None & 25 & 31.3 & 2.32 & & 2.40 & & 0.64 & & 0.68 & & -1.40 & \\
\hline
\end{tabular}




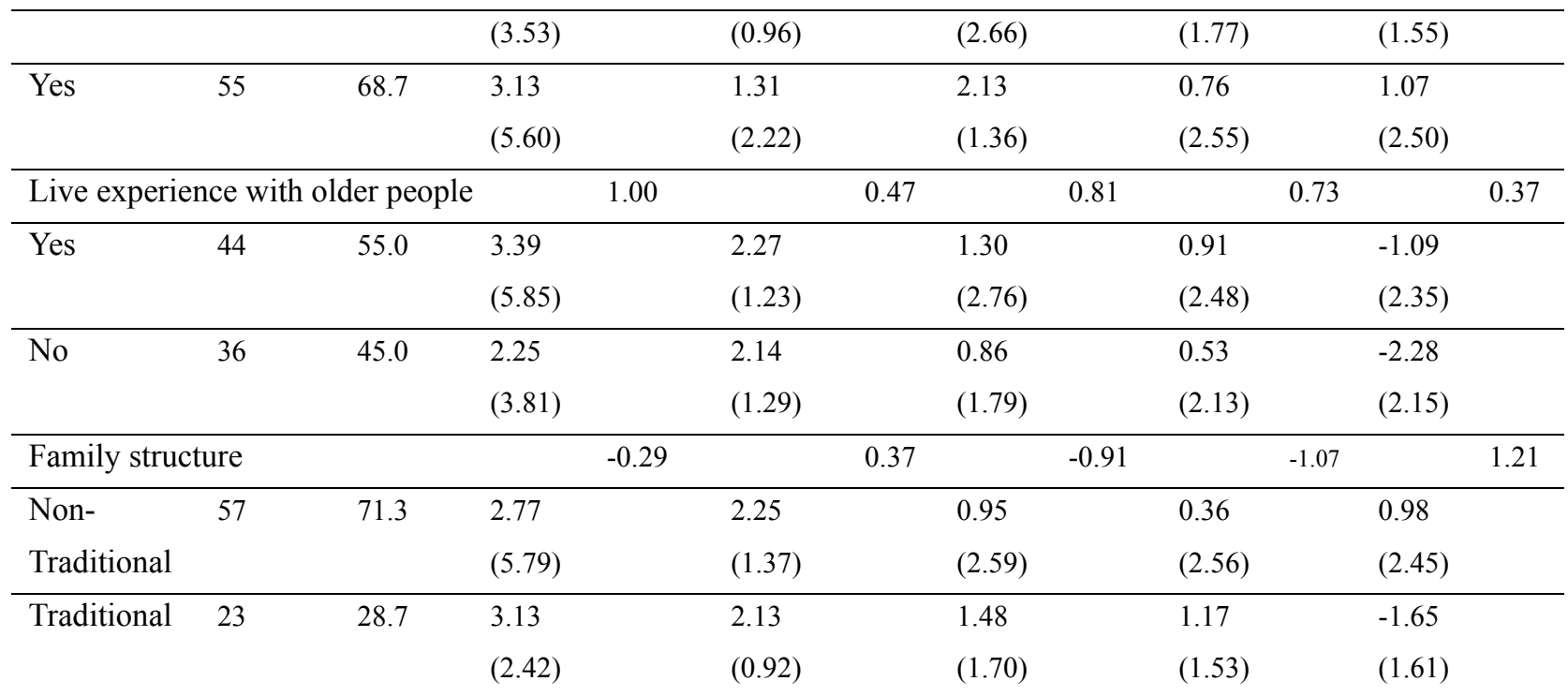

\section{Professional characteristics}

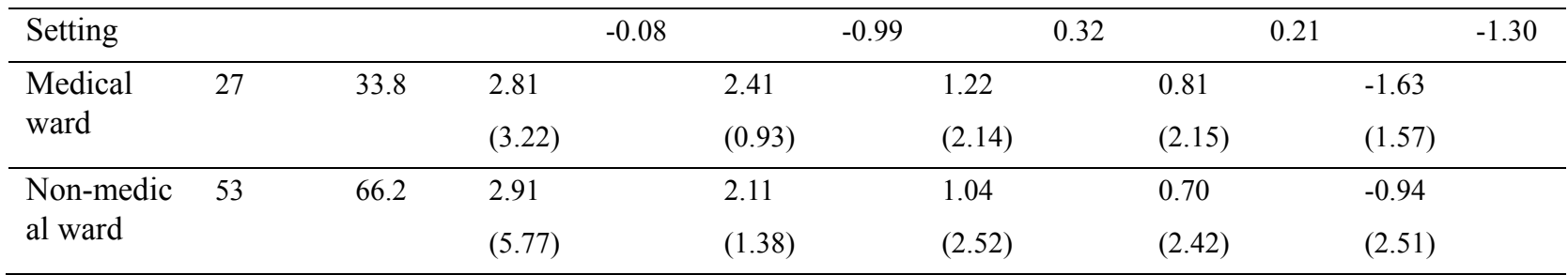

\begin{tabular}{|c|c|c|c|c|c|c|c|c|c|c|c|c|}
\hline & \multirow{2}{*}{$\begin{array}{l}\text { Frequency } \\
(n)\end{array}$} & \multirow{2}{*}{$\begin{array}{l}\text { Percent } \\
\%\end{array}$} & \multicolumn{2}{|c|}{ knowledge } & \multicolumn{2}{|c|}{ Physical } & \multicolumn{2}{|c|}{ psychological } & \multicolumn{2}{|c|}{ society } & \multicolumn{2}{|c|}{ epidemiological } \\
\hline & & & $\begin{array}{l}\text { Mean } \\
(S D)\end{array}$ & $t / F$ & $\begin{array}{l}\text { Mean } \\
(S D)\end{array}$ & $t / F$ & $\begin{array}{l}\text { Mean } \\
(S D)\end{array}$ & $t / F$ & $\begin{array}{l}\text { Mean } \\
(S D)\end{array}$ & $t / F$ & $\begin{array}{l}\text { Mean } \\
(S D)\end{array}$ & $t / F$ \\
\hline Working po & ition & & & 0.70 & & -0.79 & & -0.28 & & 1.88 & & 0.39 \\
\hline Manager & 7 & 8.8 & $\begin{array}{l}4.4 \\
(1.86)\end{array}$ & & $\begin{array}{l}1.86 \\
(1.07)\end{array}$ & & $\begin{array}{l}0.86 \\
(1.57)\end{array}$ & & $\begin{array}{l}2.29 \\
(0.76)\end{array}$ & & $\begin{array}{l}-0.86 \\
(1.46)\end{array}$ & \\
\hline $\begin{array}{l}\text { Registered } \\
\text { Nurse }\end{array}$ & 73 & 91.2 & $\begin{array}{l}2.75 \\
(5.23)\end{array}$ & & $\begin{array}{l}2.25 \\
(1.27)\end{array}$ & & $\begin{array}{l}1.12 \\
(2.44)\end{array}$ & & $\begin{array}{l}0.59 \\
(2.37)\end{array}$ & & $\begin{array}{l}-1.12 \\
(2.32)\end{array}$ & \\
\hline Working ex & erience & & & 0.07 & & -0.85 & & 0.56 & & 0.68 & & -0.66 \\
\hline$<=3$ years & 19 & 23.8 & $\begin{array}{l}2.95 \\
(3.98)\end{array}$ & & $\begin{array}{l}1.86 \\
(1.05)\end{array}$ & & $\begin{array}{l}1.37 \\
(2.11)\end{array}$ & & $\begin{array}{l}1.05 \\
(2.44)\end{array}$ & & $\begin{array}{l}-1.47 \\
(1.78)\end{array}$ & \\
\hline$>3$ years & 61 & 76.2 & $\begin{array}{l}2.85 \\
(5.35)\end{array}$ & & $\begin{array}{l}2.28 \\
(1.31)\end{array}$ & & $\begin{array}{l}1.02 \\
(2.45)\end{array}$ & & $\begin{array}{l}0.64 \\
(2.30)\end{array}$ & & $\begin{array}{l}-1.08 \\
(2.38)\end{array}$ & \\
\hline
\end{tabular}

\section{Educational background}

\begin{tabular}{|c|c|c|c|c|c|c|c|c|c|c|c|c|}
\hline \multicolumn{4}{|c|}{ Level of education } & 0.28 & & -0.66 & & -0.80 & & 1.37 & & 0.42 \\
\hline \multirow{2}{*}{$\begin{array}{l}\text { Junior } \\
\text { college }\end{array}$} & \multirow[t]{2}{*}{53} & \multirow[t]{2}{*}{66.3} & 0.31 & & 2.19 & & -0.06 & & 0.16 & & -1.97 & \\
\hline & & & $(3.00)$ & & (1.33) & & (2.23) & & $(1.87)$ & & (1.84) & \\
\hline \multirow[t]{2}{*}{ University } & \multirow[t]{2}{*}{27} & \multirow[t]{2}{*}{33.7} & 0.06 & & 2.49 & & 0.44 & & -0.63 & & -2.19 & \\
\hline & & & (2.57) & & $(1.03)$ & & $(1.55)$ & & $(1.86)$ & & $(1.38)$ & \\
\hline \multicolumn{4}{|c|}{ Studied experience of gerontology } & 0.58 & & -1.35 & & 0.65 & & 1.21 & & 0.10 \\
\hline Yes & 40 & 50.0 & 3.20 & & 2.03 & & 1.28 & & 1.05 & & -1.15 & \\
\hline
\end{tabular}




\begin{tabular}{|c|c|c|c|c|c|c|c|c|c|c|c|c|}
\hline & & & $(5.31)$ & & $(1.49)$ & & $(2.24)$ & & $(2.65)$ & & $(2.29)$ & \\
\hline \multirow[t]{2}{*}{ No } & \multirow[t]{2}{*}{40} & \multirow[t]{2}{*}{50.0} & 2.55 & & \multicolumn{2}{|l|}{2.40} & \multicolumn{2}{|l|}{0.93} & \multicolumn{2}{|l|}{0.43} & \multicolumn{2}{|l|}{-1.20} \\
\hline & & & $(4.79)$ & & $(0.93)$ & & $(2.50)$ & & $(1.92)$ & & $(2.23)$ & \\
\hline \multicolumn{3}{|c|}{ Preferred care older people } & & 0.15 & & -1.11 & & -0.82 & & 0.11 & & 1.73 \\
\hline \multirow[t]{2}{*}{ Yes } & 6 & 7.5 & 3.17 & & 1.67 & & 0.33 & & 0.83 & & 0.33 & \\
\hline & & & $(1.47)$ & & $(1.21)$ & & $(1.75)$ & & $(1.47)$ & & $(0.52)$ & \\
\hline \multirow[t]{2}{*}{ No } & 74 & 92.5 & 2.85 & & 2.26 & & 1.16 & & 0.73 & & -1.30 & \\
\hline & & & $(5.23)$ & & $(1.25)$ & & $(2.41)$ & & $(2.38)$ & & $(2.29)$ & \\
\hline \multicolumn{3}{|c|}{ Gerontological CPD } & & 1.21 & & $2.75 * *$ & & 0.16 & & 0.65 & & 0.40 \\
\hline \multirow[t]{2}{*}{ None } & 68 & 85.0 & 3.16 & & 1.33 & & 1.18 & & 0.81 & & -1.13 & \\
\hline & & & $(5.18)$ & & $(1.56)$ & & $(2.46)$ & & $(2.33)$ & & $(2.25)$ & \\
\hline \multirow[t]{2}{*}{ Yes } & 12 & 15.0 & 1.25 & & 2.37 & & 1.00 & & 0.33 & & -1.42 & \\
\hline & & & $(3.96)$ & & $(1.31)$ & & (1.86) & & $(2.31)$ & & $(2.35)$ & \\
\hline
\end{tabular}

Note: Abbreviation: $\mathrm{SD}=$ Standard Deviation $;{ }^{*} \mathrm{p}<.05 ; * * \mathrm{p}<.01 ; * * * \mathrm{p}<.001$

\subsection{Knowledge}

The mean knowledge of older people score was $0.12 \pm 0.20$ (all scores ranged from -1 to 1 , where 1 represented that all the answers are correct). The highest scores were obtained in the knowledge of physical aspects $(0.74 \pm$ $0.42)$, while the lowest was in epidemiological aspects $(-0.17 \pm 0.32)$.

A score of 25 was equivalent to $100 \%$, and the rate of correct scores was $55.76 \%$. The results indicated that nurses had low knowledge on aging as measured by PFAQ.

\subsection{Attitude}

The mean score on attitude toward older adults was $2.68 \pm 0.21$. The highest scores were seen in the positive attitude towards older adults $(2.58 \pm 0.32)$, with a range of 34 to 136 . The mean score for all 80 participants was $91.29(\mathrm{SD}=7.10)$. Their lowest attitude score was $77.0(\mathrm{n}=1)$ while the highest was $108.0(\mathrm{n}=1)$. A total score of 136 was equivalent to 100 , while the average score was 66.91 . The results indicated that nurses tend to have positive attitudes towards older adults.

\subsection{Association Between Demographic and Professional Characteristics and Attitude Scores}

In Table 2, the results demonstrated no significant differences in the total score after considering the relevant demographic and professional characteristics. However, on general attitude, participants without gerontological CPD demonstrated significantly better attitude than those with CPD experience.

Table 2. Participants' attitude toward the elderly $(\mathrm{n}=80)$

\begin{tabular}{|c|c|c|c|c|c|c|}
\hline & \multicolumn{2}{|c|}{ General Attitude } & \multicolumn{2}{|c|}{ Positive attitude } & \multicolumn{2}{|c|}{ Negative attitude } \\
\hline & $\begin{array}{l}\text { Mean } \\
(S D)\end{array}$ & $t / F$ & $\begin{array}{l}\text { Mean } \\
(S D)\end{array}$ & $t / F$ & $\begin{array}{l}\text { Mean } \\
(S D)\end{array}$ & $t / F$ \\
\hline \multicolumn{7}{|c|}{ Socio-demographic characteristics } \\
\hline Age & & 1.09 & & 1.85 & & 0.49 \\
\hline$\langle=25 \mathrm{y} / \mathrm{o}$ & $\begin{array}{l}2.73 \\
(0.23)\end{array}$ & & $\begin{array}{l}2.70 \\
(0.28)\end{array}$ & & $\begin{array}{l}2.24 \\
(0.24)\end{array}$ & \\
\hline$>25 \mathrm{y} / \mathrm{o}$ & $\begin{array}{l}2.67 \\
(0.20)\end{array}$ & & $\begin{array}{l}2.54 \\
(0.32)\end{array}$ & & $\begin{array}{l}2.20 \\
(0.26)\end{array}$ & \\
\hline Religious & & -0.04 & & -0.34 & & -0.35 \\
\hline None & 2.68 & & 2.56 & & 2.26 & \\
\hline
\end{tabular}




\begin{tabular}{|c|c|c|c|c|c|c|}
\hline & $(0.18)$ & & $(0.36)$ & & $(0.25)$ & \\
\hline \multirow[t]{2}{*}{ Yes } & 2.69 & & 2.59 & & 2.22 & \\
\hline & $(0.22)$ & & $(0.30)$ & & $(0.26)$ & \\
\hline \multicolumn{2}{|c|}{ Live experience with older people } & 0.77 & & 0.75 & & -0.32 \\
\hline \multirow[t]{2}{*}{ Yes } & 2.70 & & 2.60 & & 2.20 & \\
\hline & $(0.21)$ & & $(0.32)$ & & $(0.22)$ & \\
\hline \multirow[t]{2}{*}{ No } & 2.67 & & 2.55 & & 2.22 & \\
\hline & $(0.21)$ & & $(0.32)$ & & $(0.30)$ & \\
\hline Family structure & & -1.06 & & -1.57 & & -0.21 \\
\hline \multirow[t]{2}{*}{ Non-Traditional } & 2.67 & & 2.54 & & 2.21 & \\
\hline & $(0.21)$ & & $(0.34)$ & & $(0.27)$ & \\
\hline \multirow[t]{2}{*}{ Traditional } & 2.72 & & 2.67 & & 2.22 & \\
\hline & $(0.22)$ & & $(0.26)$ & & $(0.21)$ & \\
\hline
\end{tabular}

\section{Professional characteristics}

\begin{tabular}{|c|c|c|c|c|c|c|}
\hline Setting & & 0.61 & & 0.68 & & -0.14 \\
\hline \multirow[t]{2}{*}{ Medical ward } & 2.70 & & 2.61 & & 2.20 & \\
\hline & $(0.21)$ & & $(0.27)$ & & $(0.23)$ & \\
\hline \multirow[t]{2}{*}{ Non-medical ward } & 2.67 & & 2.56 & & 2.21 & \\
\hline & $(0.21)$ & & $(0.34)$ & & $(0.27)$ & \\
\hline Working position & & 1.69 & & 1.54 & & -0.82 \\
\hline \multirow[t]{2}{*}{ Manager } & 2.81 & & 2.76 & & 2.13 & \\
\hline & $(0.10)$ & & $(0.14)$ & & $(0.12)$ & \\
\hline \multirow[t]{2}{*}{ Registered Nurse } & 2.67 & & 2.56 & & 2.22 & \\
\hline & $(0.21)$ & & $(0.33)$ & & $(0.26)$ & \\
\hline Working experience & & 0.28 & & 0.76 & & 0.49 \\
\hline \multirow[t]{2}{*}{$\langle=3$ years } & 2.70 & & 2.63 & & 2.23 & \\
\hline & $(0.22)$ & & $(0.31)$ & & $(0.24)$ & \\
\hline \multirow[t]{2}{*}{$>3$ years } & 2.68 & & 2.57 & & 2.20 & \\
\hline & $(0.21)$ & & $(0.32)$ & & $(0.26)$ & \\
\hline
\end{tabular}

\begin{tabular}{|c|c|c|c|c|c|c|}
\hline \multicolumn{7}{|c|}{ Educational background } \\
\hline Level of educa & & 0.19 & & -0.55 & & -1.00 \\
\hline \multirow[t]{2}{*}{ Junior college } & 2.67 & & 2.57 & & 2.19 & \\
\hline & $(0.20)$ & & $(0.34)$ & & $(0.26)$ & \\
\hline \multirow[t]{2}{*}{ University } & 2.68 & & 2.61 & & 2.25 & \\
\hline & $(0.23)$ & & $(0.28)$ & & $(0.24)$ & \\
\hline \multicolumn{2}{|c|}{ Studied experience of gerontology } & 0.30 & & 0.68 & & 0.36 \\
\hline \multirow[t]{2}{*}{ Yes } & 2.69 & & 2.60 & & 2.22 & \\
\hline & $(0.23)$ & & $(0.33)$ & & $(0.28)$ & \\
\hline \multirow[t]{2}{*}{ No } & 2.68 & & 2.56 & & 2.20 & \\
\hline & $(0.19)$ & & $(0.31)$ & & $(0.23)$ & \\
\hline
\end{tabular}




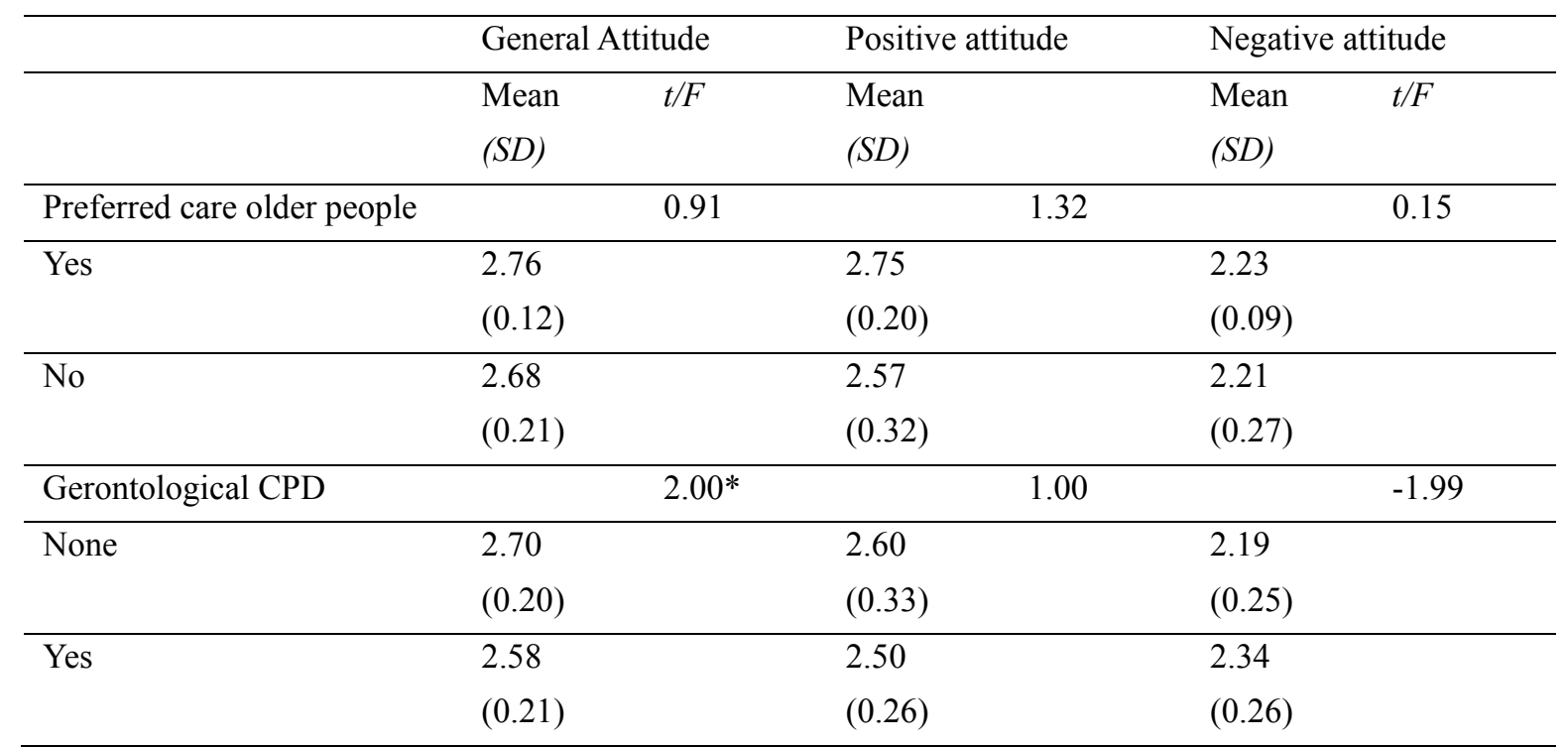

Note: Abbreviation: $\mathrm{SD}=$ Standard Deviation; ${ }^{*} \mathrm{p}<.05 ; * * \mathrm{p}<.01 ; * * * \mathrm{p}<.001$

\subsection{The Correlation Between the Knowledge and Attitudes of Nurses Towards Older Adults}

Bivariate associations between the knowledge and attitudes of nurses towards older adults were shown in Table 3. The significant positive correlations were between subjective knowledge and attitudes of nurses towards older adults $(\mathrm{r}=0.404, \mathrm{p}<.01)$. Moreover, the significant positive correlations were between subjective knowledge of psychological aspects, societal aspects, epidemiological aspects, and positive attitudes towards older adults $(\mathrm{r}=$ $0.376,0.300,0.326, p<.01$, respectively). However, there were non-significant correlations between knowledge and negative attitudes of nurses towards older adults.

\section{Discussion}

\subsection{Nurses' Knowledge About Aging}

The results indicated that the participating nurses in this study had low knowledge about aging. Their knowledge rate was lower as compared to other studies which also used the PFAQ scale (DeWitt \& Matre, 1988; Glasspoole \& Aman, 1990; Harrison \& Novak, 1988; Holtzman \& Beck, 1979; Huckstadt, 1983; Mellor et al., 2007; Palmore, 1977; Ross, 1983; Shahidi \& Devlen, 1993). However, the results were similar to those of Steele (1978), where the knowledge rates of dental students was 59\%, and Edward et al. (1992) who reported a rate of $56 \%$, and Liu (2015) who reported 50.26\%.

The results of this study may be related to the fact that most of the subjects have never had gerontological nursing education or gerontological CPD. In fact, a Taiwanese study pointed out that among the 552 hospital staff, only $43.48 \%$ of the subjects had taken gerontological courses in school, while only $30.62 \%$ had received gerontological CPD within one year, which is equivalent to those who preferred working with older patients (Chao et al., 2018). Thus, it is necessary to promote gerontological education in the field of nursing. However, gerontological nursing is only an elective subject which is not required by the Senior Professional and Technical Examinations Regulations in Taiwan. Hence, studies suggested that elderly-related curricula should be promoted, including CPD, to meet the increasing demands of elderly healthcare (Lee et al., 2012; Zverev, 2013). Moreover, Caris-Verhallen and Kazanowski (1994) suggested providing gerontological educational programs and work experience for all nurses to build self-confidence, self-esteem, and leadership skills.

On the four aspects, the respondents had a higher average knowledge rate for physical aspects $(80.83 \%)$, than for psychological aspects (43.78\%), social aspects (40.73\%), and epidemiological aspects $(29.31 \%)$. The results indicated that they have insufficient knowledge on older healthcare because there is little to no access to relevant information in the hospital. These data based on these results may be utilized for future actions regarding the effectiveness of gerontological nursing education.

\subsection{Nurses' Attitudes Towards Older Adults}

The respondents obtained a mean score of $91.29(\mathrm{SD}=7.10)$ out of 136. The lowest attitude score was $77.0(\mathrm{n}=$ 1) while the highest was $108.0(\mathrm{n}=1)$. The average score was $66.9 \%$, which indicated that nurses tended to have 
positive attitudes. These results support the findings of the majority of previous research (Che et al., 2018; Chu \& Wang, 2012; Wilson et al., 2018; Salin et al., 2020; Uğurlu et al., 2019; Zverev, 2013). However, this is different from the systematic review of Maximiano-Barreto et al. (2020), who analyzed seven articles and found that professionals and students in the field of healthcare have an implicitly negative attitude towards older adults.

This result may relate to cultural background. Older adults are likely to occupy a position of respect and honor mainly because of the lingering influence of Confucianism and the tradition of ancestral worship in Taiwan (Tsai et al., 2008). In Confucian society, behavior is guided by a clearly defined order of superiority and subordination towards the young and old. Taiwan even has a national "Day for respecting the old people" that honors older adults, where the younger generation shows their respect to the older population. In a study that explored the perceptions of filial piety among university students, it was found that filial duty was strongly rooted in their value system since Asians have been known for their tradition of filial piety for centuries, which is based on the Confucian philosophy of respect for both the living and dead (Tsai et al., 2008). Western countries, in contrast, highlight individualism and independence. Another explanation may be the number of female participants in this study. Maximiano-Barreto et al. (2019) reported that the majority of studies conducted in developed countries found that males have higher tendency of having negative attitudes toward older adults.

Therefore, they recommended activities involving both professionals/students and older adults to reduce the negative implicit attitudes of the younger generation, and perhaps even awaken their interest in working with the older population.

\subsection{The Relationship Between Nurses' Knowledge and Attitudes Towards Older Adults}

Based on the result of the Pearson product-moment correlation coefficient, there was a significantly strong positive relationship between the knowledge and attitudes of nurses towards older adults. This finding indicated that better knowledge on aging was relative to a more positive attitude, consistent with the study of Mellor et al. (2007).

This finding may have implications on the placement of gerontological nursing courses in the nursing curricula or in-service education. Wade (1999) argued that the staff involved in caring for older adults, notwithstanding their setting, should be actively involved in gerontological education and CPD. Ridgway et al.(2018) suggested nurse education can influence changing attitudes towards older people. Moreover, Che et al. (2018), Heuer et al. (2020) and Rush et al. (2017) proposed that nurses and students need evidence-based gerontological knowledge and skills to be able to practice successfully in today's healthcare environment. Burnes et al. (2019) posit in 63 eligible studies with a total sample of 6,124 participants that ageism interventions demonstrated a strongly significant effect on attitudes, knowledge, and comfort. Hence, combined interventions, education, and intergenerational contact are associated with a substantial reduction in ageism. Thus, it should be part of an international strategy to improve perceptions of older adults and the aging process.

As laid out in the WHO principals of Healthy Aging, the health workforce for aging populations (2016) ensured all healthcare professionals are trained on gerontology and geriatrics; including core geriatrics competencies in all health and medical curricula. Existing health and medical staff need additional in-service training and continuing professional development on aging, including those required for comprehensive healthy aging assessments and integrated management of complex healthcare needs. This suggests that increased knowledge may result in more positive attitudes towards older adults. However, nursing educators and managers have generally failed to consider this. Caring for older person is complex and requires unique skills. Therefore, nurses need a comprehensive understanding of aging to increase their knowledge, while also developing their positive attitudes towards older adults.

\section{Limitations}

Due to its cross-sectional design, it is not possible to ascertain the temporal relationship between the explanatory and outcome variables. A cohort or longitudinal study is recommended to address this limitation. Furthermore, an evidence-based education intervention could be developed to enhance the knowledge of nurses on aging.

\section{Conclusion}

This was the first study that investigated the knowledge and attitudes of nurses towards older hospital patients in eastern society. In this study, $50 \%$ of the subjects had never studied gerontology. While $50 \%$ had, their exposure to geriatric nursing is only through an elective course. Thus, the students may not study as hard as for an obligatory course. Moreover, the respondents had a lower average rate for epidemiological aspects $(29.31 \%)$. Hence, it is recommended to add global epidemiological trends and concepts in hospital elderly-related CPD. Moreover, the subjects showed positive attitudes towards older adults. This indicated that nurses who had better 
knowledge about older people also had a more positive attitude. The results can be consultative for nursing educators and managers to design gerontology courses for nurses and nursing students by providing data that can be utilized in decision-making regarding the effectiveness of nursing care provided to this growing group of health care recipients.

The provision of integrated care is a key point for older adults. The WHO (2016) proposed that develop geriatric units for the management of complex cases in multidisciplinary teams and collaborative work. Our health policy has developed various healthcare models such as integrated outpatient services, age-friendly healthcare facilities, post-acute care, and a long-term care program 2.0. However, the development of these healthcare models clearly demonstrates the need for service integration (Chen, 2015). Therefore, the health professionals must be deployed in a way that helps to deliver care that is centered on older people, including working in multidisciplinary teams.

\section{Acknowledgements}

We gratefully acknowledge all participants for their generous cooperation.

\section{References}

Burnes, D., Sheppard, C., Henderson, C. R., Jr Wassel, M., Cope, R., Barber, C., \& Pillemer, K. (2019). Interventions to reduce ageism against older adults: a systematic review and meta-analysis. American Journal of Public Health, 109(8), e1-e9. https://doi.org/10.2105/AJPH.2019.305123

Campbell, M. E. (1971). Study of the attitudes of nursing personnel toward the geriatric patient. Nursing Research, 20(2), 147-151.

Caris-Verhallen, W. M., Kerkstra, A., \& Bensing, J. M. (1997). The role of communications in nursing care for elderly people: a review of the literature. Journal of Advanced Nursing, 25(5), 915-933.

Chao, P. Y., Lin, Y. H., Liang, Y. W., Kuang, S. C., \& Chang, H. F. (2018). An exploration of the knowledge, attitudes, and future intentions to work with older people among hospital personnel in hospital, ministry of health and welfare in central Taiwan. Journal of Medicine and Health, 7(2), 31-44.

Che, C. C., Chong, M. C., \& Hairi, N. N. (2018). What influences student nurses' intention to work with older people? A cross-sectional study. International Journal of Nursing Studies, 85, 61-67.

Chen, L. K. (2015). Healthcare services for older people: From fragmentation to integration. The Journal of Nursing, 62(5), 23-29. https://doi.org/10.6224/ JN.62.5.23

Chu, C. W., \& Wang, J. J. (2012). Nursing students' knowledge of and attitudes toward sexuality in the elderly. Journal of Nursing and Healthcare Research, 4(8), 306-315. https://doi.org/10.6225/JNHR.08.4.306

Courtenay, B. C., \&Weidemann, C. (1985). The effects of a "don't know" response on Palmore's facts on aging quizzes. The Gerontologist, 25(2), 177-181. https://doi.org/10.1093/geront/25.2.177

De Witt, S. C., \& Matre, M. (1988). Nursing careers working with the elderly. Western Journal of Nursing Research, 10(3), 335-343. https://doi.org/10.1177/019394598801000309

Deasey, D., Kable, A., \& Jeong, S. (2014). Influence of nurses' knowledge of ageing and attitudes towards older people on therapeutic interactions in emergency care: a literature review. Australasian Journal on Ageing, 33(4), 229-236. https://doi.org/10.1111/ajag.12169

Edwards, M. J., \& Aldous, I. R. (1996). Attitudes to and knowledge about elderly people: a comparative analysis of students of medicine, English and Computer Science and their teachers. Medical Education, 30(3), 221-225. https://doi.org/10.1111/j.1365-2923.1996.tb00746.x

Glasspoole, L. A., \& Aman, M. G. (1990). Knowledge, attitudes, and happiness of nurses working with gerontological patients. Journal of Gerontological Nursing, 16(2), 11-14. https://doi.org/10.3928/0098-9134-19900201-05

Harris, M. B., Page, P., \& Begay, C. (1988). Attitudes toward aging in a southwestern sample: effects of ethnicity, age, and sex. Psychological Reports, 62(3), 735-746. https://doi.org/10.2466/pr0.1988.62.3.735

Heller, B. R., \& Walsh, F. J. (1976). Changing nursing students' attitudes toward the aged: an experimental study. The Journal of Nursing Education, 15(1), 9-17.

Heuer, S., Douglas, N., Burney, T., \& Willer, R. (2020). Service-Learning with older adults in care communities: Measures of attitude shifts in undergraduate students. Gerontology and Geriatrics Education, 41(2), 186-199. https://doi.org/10.1080/02701960.2019.1596087

Holtzman, J. M., \& Beck, J. D. (1979). Palmore's facts on aging quiz: a reappraisal. The Gerontologist, 19(1), 
116-120. https://doi.org/10.1093/geront/19.1.116

Hope, K. W. (1994). Nurses' attitudes towards older people: a comparison between nurses working in acute medical and acute care of elderly patient settings. Journal of Advanced Nursing, 20(4), 605-612.

Huckstadt, A. A. (1983). Do nurses know enough about gerontology?. Journal of Gerontological Nursing, 9(7), 392-397. https://doi.org/10.3928/0098-9134-19830701-06

Kogan, N. (1961). Attitudes toward old people: The development of a scale and an examination of correlates. The Journal of Abnormal and Social Psychology, 62(1), 44-54.

Lee, C. Y., Hsu, H. C., Chou, Y. L., \& Chen, Y. J. (2012). Willingness and attitudes toward elderly care among nurses at a medical center in central Taiwan. Journal of Nursing and Healthcare Research, 8, 297-305. https://doi.org/10.6225/JNHR.08.4.297

Liu, H. Y. (2015). Junior college students' aging knowledge and attitude toward elderly person-a survey in one nursing junior college in Miaoli. Chinese Journal of School Health, 6(66), 69-90. https://doi.org/10.30026/CJSH.201506_(66).0004

Maximiano-Barreto, M. A., Luchesi, B. M., \& Chagas, M. (2019). Implicit attitudes toward the elderly among health professionals and undergraduate students in the health field: a systematic review. Trends in Psychiatry and Psychotherapy, 41(4), 415-421. https://doi.org/10.1590/2237-6089-2018-0108

Meisner, B. A. (2012). A meta-analysis of positive and negative age stereotype priming effects on behavior among older adults. The Journals of Gerontology, Series B, Psychological Sciences and Social Sciences, 67(1), 13-17. https://doi.org/10.1093/geronb/gbr062

Mellor, P., Chew, D., \& Greenhill, J. (2007). Nurses' attitudes toward elderly people and knowledge of gerontic care A meta-analysis of positive and negative age stereotype priming effects on behavior among older adults in a mult-purpose health service (MPHS). The Australian Journal of Advanced Nursing: A Quarterly Publication of the Royal Australian Nursing Federation, 24(4), 37-41.

Palmore, E. (1977). Facts on Aging: A Short Quiz1. The Gerontologist, 17(4), $315-320$. https://doi.org/10.1093/geront/17.4.315

Ridgway, V., Mason-Whitehead, E., \& McIntosh-Scott, A. (2018). Visual perceptions of ageing; a longitudinal mixed methods study of UK undergraduate student nurses' attitudes and perceptions towards older people. Nurse Education in Practice, 33, 63-69. https://doi.org/10.1016/j.nepr.2018.08.005

Ross, M. M. (1983). Learning to nurse the elderly: outcome measures. Journal of Advanced Nursing, 8(5), 373-378. https://doi.org/10.1111/j.1365-2648.1983.tb00460.x

Rush, K. L., Hickey, S., Epp, S., \& Janke, R. (2017). Nurses' attitudes towards older people care: An integrative review. Journal of Clinical Nursing, 26(23-24), 4105-4116. Retrieved from https://onlinelibrary.wiley.com/doi/abs/10.1111/jocn.13939

Salin, S., Hautsalo, K., Vänni, K., Seitsamo, S., \& Yli-Koivisto, L. (2020). Finnish nurse students' attitudes towards older adults and the teaching of gerontological nursing - A survey study. Nurse Education Today, 88, 104379. https://doi.org/10.1016/j.nedt.2020.104379

Shahidi, S., \& Devlen, J. (1993). Medical students' attitudes to and knowledge of the aged. Medical Education, 27(3), 286-288. https://doi.org/10.1111/j.1365-2923.1993.tb00270.x

Sheffler, S. J. (1995). Do clinical experiences affect nursing students' attitudes toward the elderly?. Journal of Nursing Education, 34(7), 312-316.

Steele, L. P. (1987). Dental students' attitudes and knowledge about elderly people. Gerodontics, 3(2), 61-64.

The Ministry of Health and Welfare, Taiwan, R. O. C. (2018). Report of the senior citizen condition survey 2017. Retrieved from https://dep.mohw.gov.tw/DOS/cp-1767-38429-113.html

The Ministry of the Interior, Taiwan, R. O. C. (2020). Statistical yearbook of interior. Retrieved from https://www.moi.gov.tw/files/site_stuff/321/2/year/year_en.html

Tsai, H. H., Chen, M. H., \& Tsai, Y. F. (2008). Perceptions of filial piety among Taiwanese university students. Journal of Advanced Nursing, 63(3), 284-290. https://doi.org/10.1111/j.1365-2648.2008.04711.x

Uğurlu, Z., Kav, S., Karahan, A., \& Akgün Çıtak, E. (2019). Correlates of ageism among health care professionals working with older adults. Journal of Transcultural Nursing, 30(3), $303-312$. https://doi.org/10.1177/1043659618810128 
Wade, S. (1999). Promoting quality of care for older people: developing positive attitudes to working with older people. Journal of Nursing Management, 7(6), 339-347. https://doi.org/10.1046/j.1365-2834.1999.00143.x

Wilson, M., Kurrle, S., \& Wilson, I. (2018). Medical student attitudes towards older people: a critical review of quantitative measures. BMC Research Notes, 11(1), 71. https://doi.org/10.1186/s13104-018-3186-z

World Health Organization. (2016). Health workforce for ageing populations. Retrieved from https:/www.who.int/ageing/publications/health_workforce_ageing/en/

World Health Organization. (2017). Global strategy and action plan on ageing and health. Retrieved from https://www.who.int/ageing/global-strategy/en/

Zverev, Y. (2013). Attitude towards older people among Malawian medical and nursing students. Educational Gerontology, 39(1), 57-66.

\section{Copyrights}

Copyright for this article is retained by the author(s), with first publication rights granted to the journal.

This is an open-access article distributed under the terms and conditions of the Creative Commons Attribution license (http://creativecommons.org/licenses/by/4.0/). 